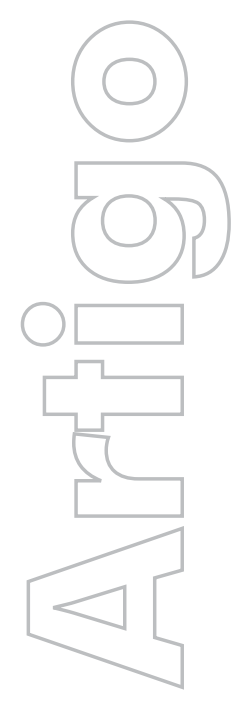

\title{
Unidades de paisagem na bacia hidrográfica do Ribeirão Preto, Serra do Gandarela-MG
}

\author{
Breno Ribeiro Marent \\ Cefet-MG
}

Sidney Portilho Uni-BH

p. $138-155$

revista

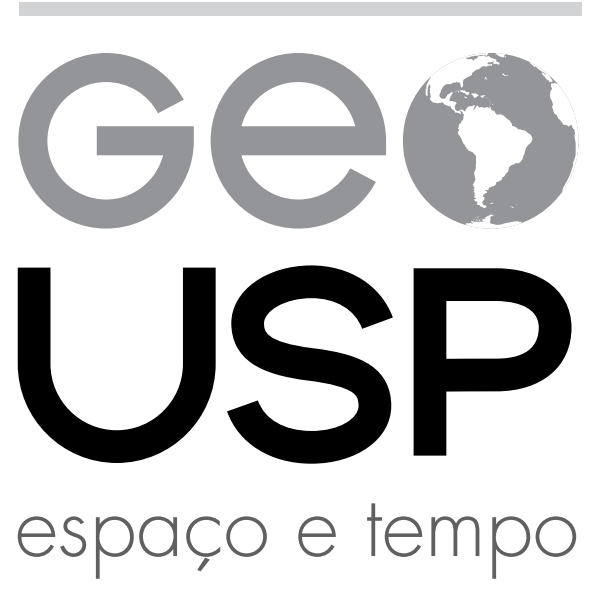

Volume $21 \cdot n^{\circ} 1(2017)$

ISSN 2179-0892
Como citar este artigo:

MARENT, B. R.; PORTILHO, S. Unidades de paisagem na bacia hidrográfica do Ribeirão Preto, Serra do Gandarela-MG. Geousp - Espaço e Tempo (Online), v. 21, n. 1, p. 138-155, abril. 2017. ISSN 2179-0892.

Disponível em: < http://www.revistas.usp.br/geousp/ article/view/116477>. doi: 10.11606/issn.2179-0892. geousp.2017.116477.

\section{(c) $(1) \Theta$}

Este artigo está licenciado sob a Creative Commons Attribution 4.0 License. 


\title{
Unidades de paisagem na bacia hidrográfica do Ribeirão Preto, Serra do Gandarela-MG
}

\section{Resumo}

Este trabalho estuda a relação entre geologia, relevo, solo, vegetação e uso da terra na bacia hidrográfica do Ribeirão Preto. Para tanto, recorreuse à abordagem geossistêmica, na qual o relevo foi o parâmetro usado para delimitar as unidades de paisagem. Esses atributos foram relacionados a partir de mapas temáticos, quadro síntese e perfil transversal. O relevo foi um parâmetro adequado para delimitar as unidades de paisagem, apresentando correlação entre os elementos analisados. O relevo movimentado está relacionado à geologia. Esses elementos condicionam a formação dos solos, predominando neossolos e cambissolos. A vegetação está relacionada à interação entre geologia, relevo e solos. As características da área a tornam extremamente frágil diante das intervenções antrópicas. Considerados importantes para a conservação, seus atributos indicam-na como propícia ao estabelecimento de unidade de conservação, permitindo a manutenção desses ambientes.

Palavras-chave: Quadrilátero Ferrífero. Geossistema. Estratificação de ambientes. Unidade de conservação. Potencialidade de áreas geográficas.

\section{Landscape units in the hydrographic basin of stream Preto, Serra do Gandarela-MG}

\begin{abstract}
This work aimed to study the relationship geology, topography, soil, vegetation and land use in the watershed of Ribeirão Preto. To achieve this goal we used an geosystemic approach in which relief was the parameter used to define the landscape units. The relations between these attributes were made from thematic maps, transverse profile and summary table. The relief was an appropriate parameter for delimiting the landscape units presented a correlation between the elements analyzed. The relief is related
\end{abstract}


to geology. Those elements influence the formation of different soils types, Entisols and Cambisols. The vegetation is related to the interaction of geology, soil and topography. The area features make it extremely fragile in the face of anthropic interventions. His attributes considered important for conservation to indicate how favorable the establishment of conservation unit, allowing the maintenance of these environments.

Keywords: Iron Quadrangle. Geosystems. Environments stratification. Conservation unit. Potential geographic areas.

\section{Introdução}

Localizada no interior do Quadrilátero Ferrífero a Serra do Gandarela configurase como uma de suas áreas mais bem preservadas. Possui estreita vinculação entre os atributos geológicos, pedológicos, geomorfológicos e fitogeográficos. Além do significativo estado de conservação, exibe uma diversidade de ambientes formada por complexa interação entre diferentes elementos do meio físico, característica típica do Quadrilátero Ferrífero. Nesse sentido, o Instituto Chico Mendes de Conservação da Biodiversidade (ICMBio) identificou a área como de "excepcionais atributos biológicos, hidrológicos, geológicos, geomorfológicos, espeleológicos, paleontológicos e históricoculturais" (ICMBio, 2010).

O resultado da interação dos elementos do meio físico na Serra do Gandarela gera uma diversidade de paisagens ainda pouco estudadas. Silva e Salgado (2009) ressaltaram a necessidade de mais estudos devido à complexidade da região e do conflito de interesses na área (exploração mineral e a criação de unidades de conservação). Em 2009, foi proposto para uma porção da Serra do Gandarela um grande projeto de mineração que poderia comprometer significativamente seus recursos naturais. Em 2010, foi proposto a criação de um parque nacional (ICMBio, 2010) abrangendo uma área daquele projeto. Até o momento o impasse permanece, não sendo aprovada medida que favoreça um (mineração) ou outro interesse (criação de uma unidade de conservação). No entanto, conforme decisão da justiça federal que determinou em junho de 2012 a criação do Parque Nacional do Gandarela, (Fraga; Ayer, 2012), existe a iminente possibilidade da região se tornar uma unidade de conservação $(\mathrm{UC})$ de proteção integral ou um mosaico de UC's de proteção integral e de uso sustentável.

Nesse contexto, insere-se este trabalho tem o objetivo de investigar as relações entre geologia, relevo, solo, cobertura vegetal e uso da terra por meio de abordagem geossistêmica na bacia do Ribeirão Preto. Essas relações foram analisadas a partir de unidades de paisagem delimitadas em função do relevo, representadas por um conjunto 
de formas semelhantes. É uma bacia hidrográfica desprovida de assentamentos populacionais e, segundo ICMBio (2010), de grande extensão contínua de floresta estacional semidecidual, incluindo ocorrências de mata primária, campos rupestres sobre substrato ferruginoso, com espécies endêmicas, além de elevada quantidade de cavidades naturais e nascentes. Esses atributos considerados de importância para conservação reúnem-se numa mesma área em que se estabelece disputa entre projetos minerários e de criação de parque nacional. O melhor conhecimento da Serra do Gandarela como paisagem integrada pode colaborar com o planejamento, manejo e gestão ambiental adequado de seus recursos naturais.

\section{Estudos da paisagem}

Nos estudos da paisagem, Sotchava (1977) ao tratar das relações entre os elementos do meio físico cria o termo geossistema em 1960. Para ele, o papel da abordagem geossistêmica é o de estudar conexões entre os componentes da natureza por meio de sua dinâmica e estrutura funcional.

Para Bertrand (1972), o geossistema é uma escala de análise de unidades de paisagem em que pode ser observada a maior parte das interações entre os seus elementos. Esta escala de paisagem é definida em função de unidades dimensionais do relevo e resulta da interação dinâmica de elementos físicos, biológicos e antrópicos interagindo uns sobre os outros. Para o autor, a sobreposição dos diferentes elementos para identificar uma unidade média acaba sendo um problema por não demonstrar nenhuma realidade.

Monteiro (2001) coloca o geossistema como a integração dos diferentes elementos da paisagem. Ele também aponta como problema a questão da delimitação das unidades de paisagem. Em sua concepção, devido à natureza integrada dos geossistemas esses não poderiam ser delimitados a partir do relevo, clima, vegetação etc. Entretanto, considera que em cada caso um desses elementos pode se destacar na paisagem, tornando-se o melhor critério para delimitar as diferentes unidades (de paisagem, geoecológicas, homogêneas, geossistêmicas etc.). Para ele, a compreensão das relações na paisagem tem que ser representada por algo que promova um apelo visual incisivo e apresente a complexidade sistêmica destas interações.

\section{Caracterização da área}

A Serra do Gandarela está localizada na porção centro-nordeste do Quadrilátero Ferrífero, entre a Serra da Piedade e a Serra do Caraça (Figura 1). A área de estudo localiza-se na porção SW da Serra, em seu ponto mais elevado, chegando a atingir os $1.660 \mathrm{~m}$ de altitude (Figuras 1 e 2). Essa área pertence ao município de Santa Bárbara e se configura como divisor hidrográfico de duas importantes bacias, do rio das Velhas, a oeste, e Doce, a leste. 


\section{Figura 1}

Mapa geológico do Quadrilátero Ferrífero e de localização da área de estudo

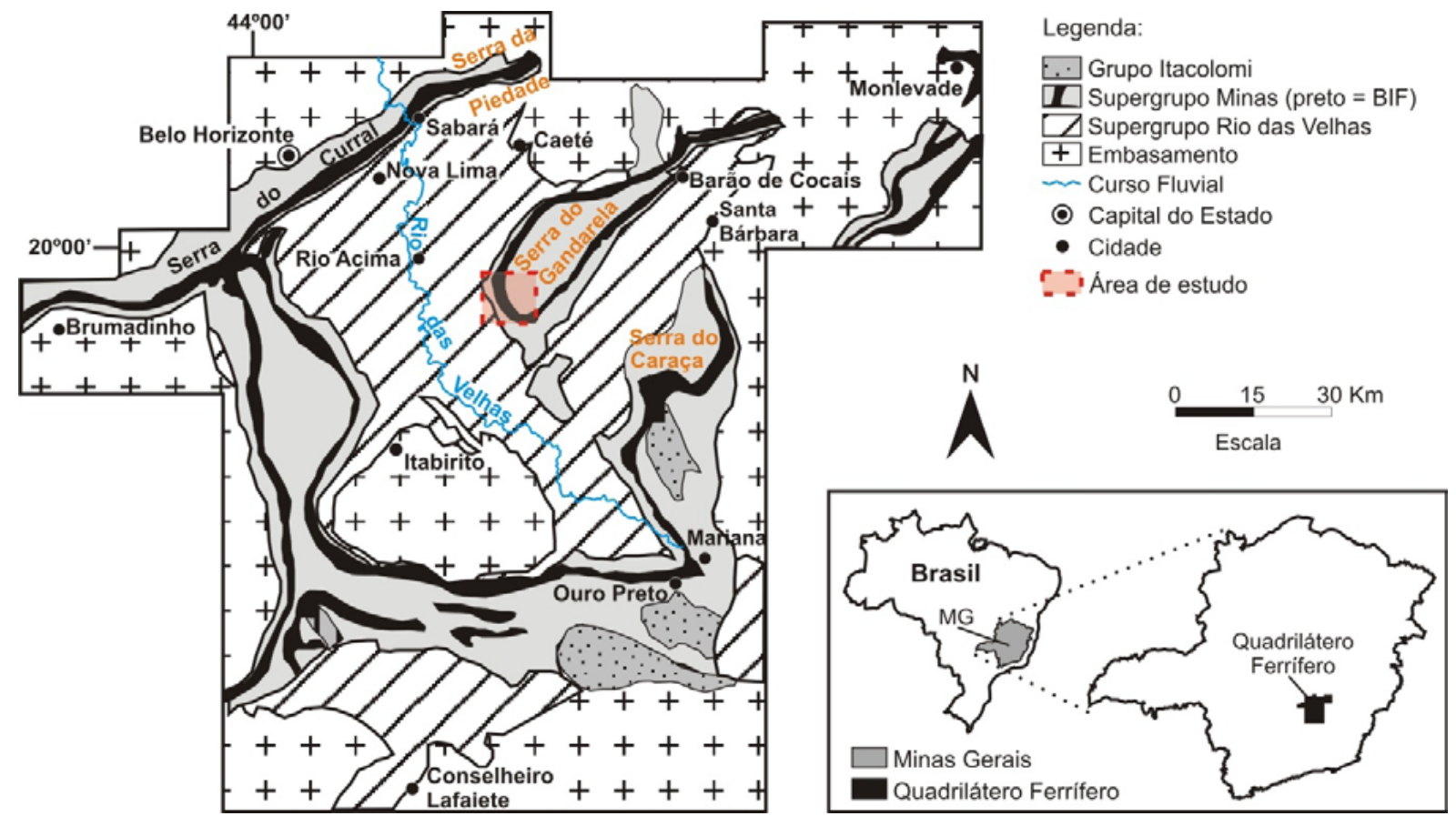

fonte: adaptado de Alkmim e Marshak (1998).

\section{Figura 2}

Mapa hipsométrico da Serra do Gandarela com localização da bacia do Ribeirão Preto e principais drenagens
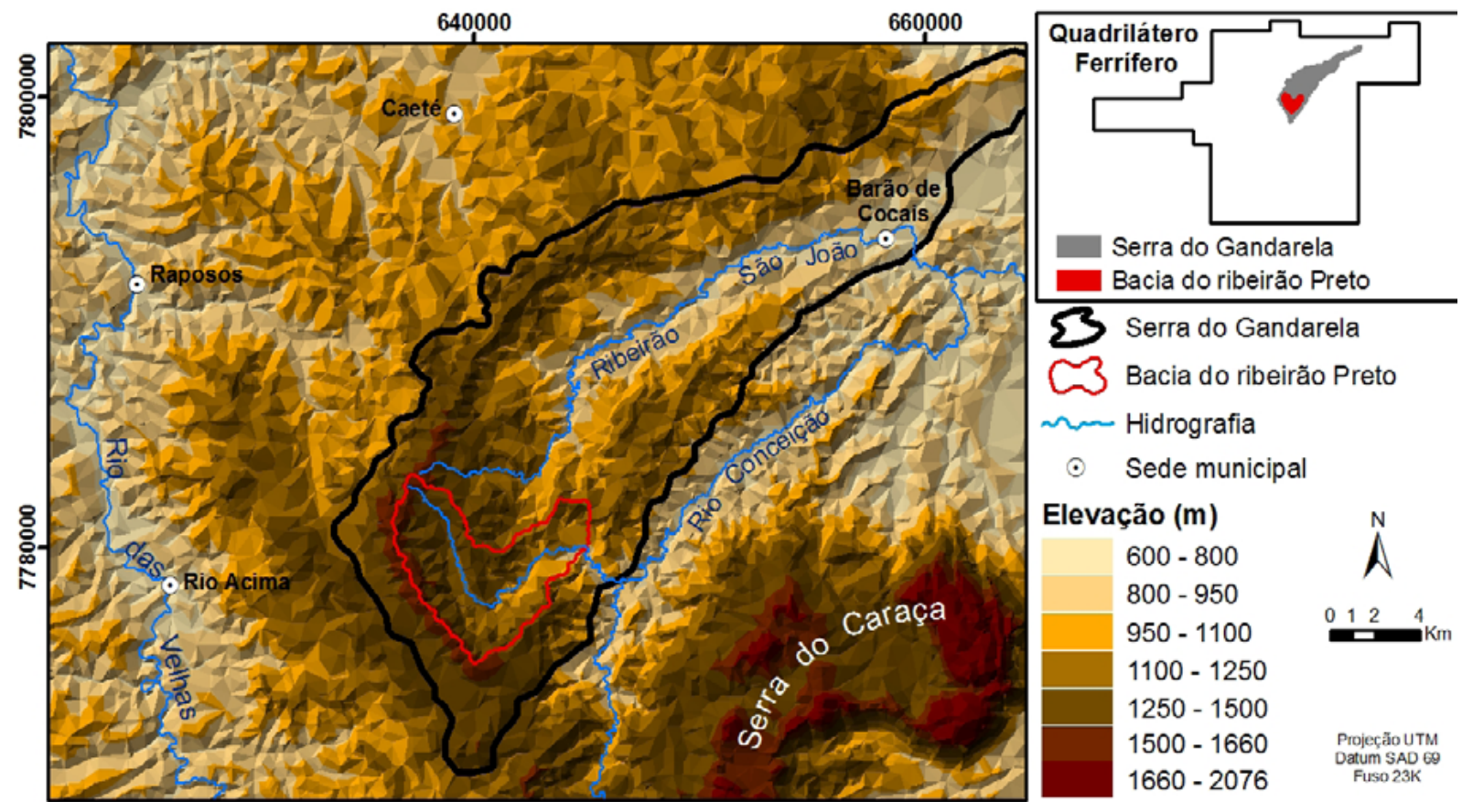
A Serra do Gandarela que se insere em estrutura geológica de mesmo nome (Sinclinal Gandarela) apresenta orientação SW-NE, sendo mais larga na porção SW e mais estreita a NE, exibindo caimento de SW para NE (Figura 2). É composta basicamente pelo Supergrupo Rio das Velhas e pelo Supergrupo Minas (Figura 1). O Supergrupo Minas compreende as porções superiores do relevo, constituído por escarpas e cristas, além das porções inferiores que se encontram no interior da Sinclinal. O Supergrupo Rio das Velhas compreende as escarpas exteriores da Sinclinal em suas porções medianas e inferiores (Lamounier et al., 2010). As rochas mais resistentes, como os itabiritos e os quartzitos, ocupam as partes mais elevadas do relevo, enquanto os xistos e os filitos, de resistência mediana, ocupam as porções medianas e inferiores do relevo (Varajão, 1991; Salgado et al., 2008).

Os solos que predominam são os neossolos e cambissolos, associados a relevo forte ondulado a montanhoso (Shinzato; Carvalho Filho, 2005). Estes solos associados ao material de origem e à topografia geram uma diversidade de formações vegetais. Nesse contexto, segundo Lamounier e outros (2010), encontram-se os campos rupestres nas partes mais elevadas do relevo, normalmente associados às cangas, itabiritos e quartzitos. Campos limpos e campos sujos estão em posição inferior do relevo em relação aos campos rupestres sobre os xistos, filitos e quartzitos filíticos do Supergrupo Rio das Velhas. A floresta estacional semidecidual ocorre na maior parte da Serra, nas rochas menos resistentes do Supergrupo Minas, como os filitos e dolomitos, e Supergrupo Rio das Velhas, como xistos e filitos.

Segundo Lamounier e outros (2010), intervenções antrópicas também são observadas na Serra do Gandarela. São representadas pela mineração, plantio de eucalipto, pastagem e atividades agrícolas. As alterações relacionadas a atividades agrícolas e pastagens encontram-se associadas a rochas do embasamento e filitos dos grupos Nova Lima e Piracicaba, em porções mais baixas do relevo. A monocultura de eucalipto se encontra relacionada a filitos dos grupos Nova Lima e Piracicaba, porém em porções inferiores e intermediárias do relevo. Já as áreas ocupadas pela mineração encontram-se nas porções superiores, associadas às rochas do Supergrupo Minas Grupo Itabira. A mineração de ferro e bauxita localiza-se sobre as cangas e itabiritos, enquanto a extração de mármores sobre os dolomitos. Porém, o que mais se destaca na área não são as atividades antrópicas e sim seu alto grau de conservação, representada principalmente pelas áreas com floresta estacional semidecidual. Além disso, as cangas e itabiritos que se encontram nas porções superiores do relevo são também os locais onde se encontram os campos rupestres e as áreas de recarga dos aquíferos, áreas prioritárias à conservação e à extração do minério de ferro.

\section{Materiais e métodos}

A escolha dessa bacia - Ribeirão Preto - como área de estudo se deu em virtude de apresentar interação bem marcada na paisagem entre os elementos do seu meio 
físico. Compreende diversidade litológica de rochas com diferentes resistências que permitiram a instalação de morfologia com compartimentos elevados, intermediários e mais rebaixados. Estes dois importantes fatores de formação dos solos (geologia e relevo) acabaram por se refletir na espessura do manto de alteração. A relação entre geologia e relevo é responsável por uma variação de ambientes geopedológicos que permite a existência de vegetação diversificada em mesma área, possibilita a presença de espécies de floresta estacional semidecidual, campos limpo, sujo e rupestre.

A execução do trabalho seguiu a proposta de Monteiro (2001) abrangendo as seguintes etapas: (i) levantamento bibliográfico para embasamento dos trabalhos e posteriores discussões; (ii) trabalho de campo, de modo a fornecer uma visão geral da área objeto de estudo; (iii) análise de mapa geológico, na escala 1:50.000 (Lobato et al., 2005); (iv) análise de bases topográficas geradas a partir da base Geominas, na escala 1:50.000, mapa geomorfológico, na escala 1:60.000 (Medina; Dantas; Saadi, 2005); (v) análise de mapa pedológico na escala 1:50.000 (Shinzato; Carvalho Filho, 2005) e; (vi) análise de mapa da classificação da cobertura vegetal e uso da terra, na escala 1:50.000, por meio de imagens Landsat 7 de maio de 2001 (Oliveira; Jacques; Shinzato, 2005). Estas escalas foram escolhidas por serem as mais detalhadas dentro dos levantamentos que se teve acesso e poderiam representar a maior quantidade de contrastes dentro de um mesmo elemento.

A partir destas bases, com o auxílio do software ArcGIS 9.3, foram elaborados mapas da bacia hidrográfica selecionada: geológico, de declividade, hipsométrico, geomorfológico, pedológico e de classificação da cobertura vegetal e uso da terra. $\bigcirc$ mapa geomorfológico foi adaptado a partir de trabalhos de campos e análises das cartas topográficas e de declividade visando a atender melhor a escala de trabalho. O mapa de cobertura vegetal e uso da terra também foi adaptado a partir de observações sobre alterações na cobertura vegetal. Foi traçado 01 (um) transecto no sentido E-W sobre os mapas de geologia, relevo, solo, vegetação e uso da terra, com o intuito de contemplar a maior variedade dos atributos físicos. A partir dos mapas base, transecto, observações em campo e das pesquisas bibliográficas este trabalho traçou as relações entre o substrato geológico, relevo, solo, vegetação e o uso da terra pela compartimentação do relevo. Estas relações foram sintetizadas em unidades de paisagens nas quais foram identificadas e caracterizadas por meio de quadro síntese. Por fim, procurou-se apresentar uma proposta de síntese das unidades de paisagem por meio de bloco-diagrama.

\section{Resultados e discussão}

A relação entre os elementos do meio físico se fez pela análise dos mapas geológico (Figura 3), hipsométrico (Figura 4), de declividade (Figura 5), pedológico (Figura 6), da cobertura vegetal e uso da terra (Figura 7) e geomorfológico (Figura 8), além de trabalhos de campo na área de estudo. 


\section{Figura 3}

\section{Mapa geológico da bacia do Ribeirão Preto}

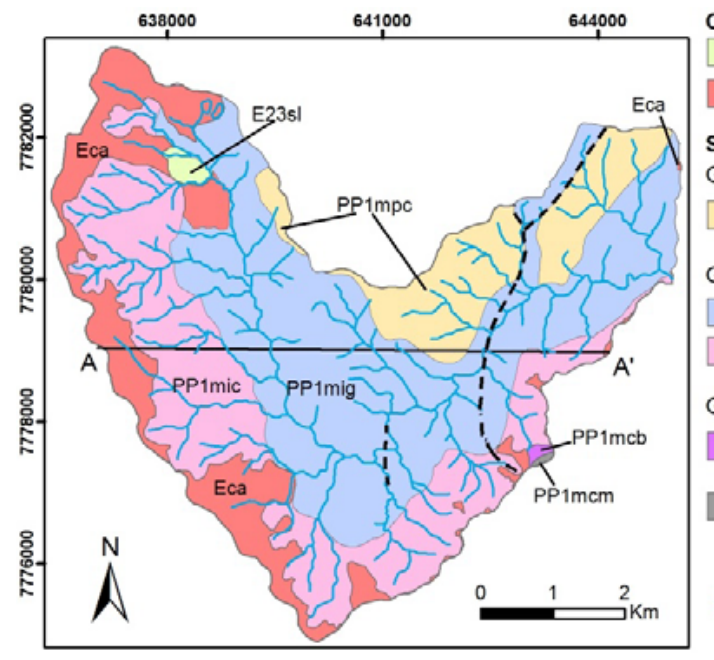

Cenozóico

Sedimento lacustre: argilito, arenito e linhito - E23sl

Canga: fragmentos de rocha cimentados por limonita - Eca

Supergrupo Minas

Grupo Piracicaba

Formação Cercadinho - Quartzito ferruginoso,quartzito,grit,quartzo sericita xisto,

filito, sericita xisto, talco xisto e grafita xisto - PP1mpc

Grupo Itabira

Formação Gandarela - Dolomito, itabirito dolomítico, calcário e filito - PP1mig

Formação Cauê - Itabirito e itabirito dolomítico, com lentes de dolomito - PP1mic Grupo Caraça

Formação Batatal - Filito sericítico, filito carbonoso, lente de quartzito fino e de formação ferrifera - PP1mcb

Formação Moeda - Quartzito cinza, grit e conglomerado, quartzo-sericita xisto com lentes de filito intercaladas - PP1 $\mathrm{mcm}$

ヘ Falhas

$\sim$ Drenagem

- Perfil A - A

fonte: Lobato e outros (2005).

\section{Figura 4}

Mapa hipsométrico da bacia do Ribeirão Preto

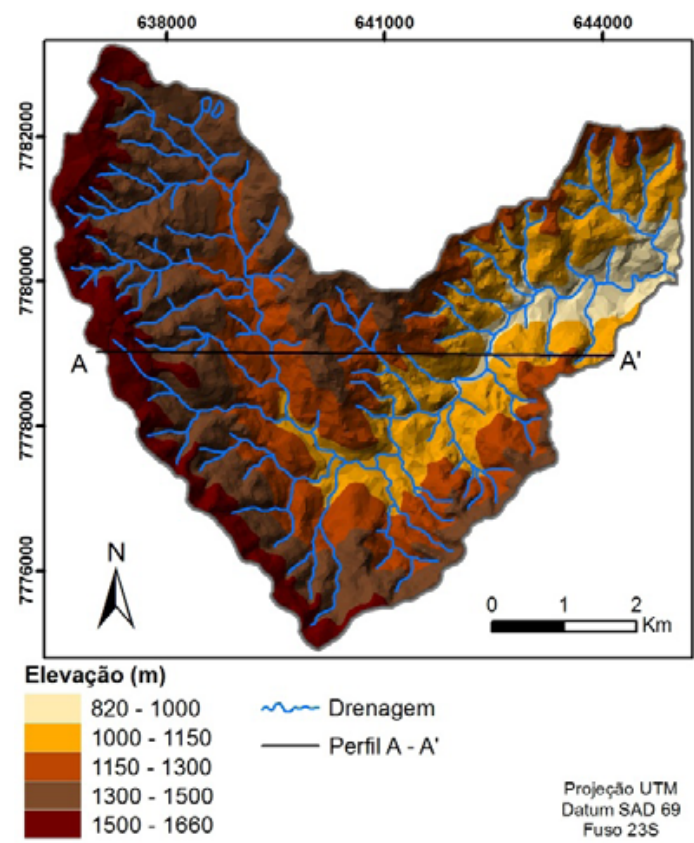

\section{Figura 5}

Mapa de declividade da bacia do Ribeirão Preto

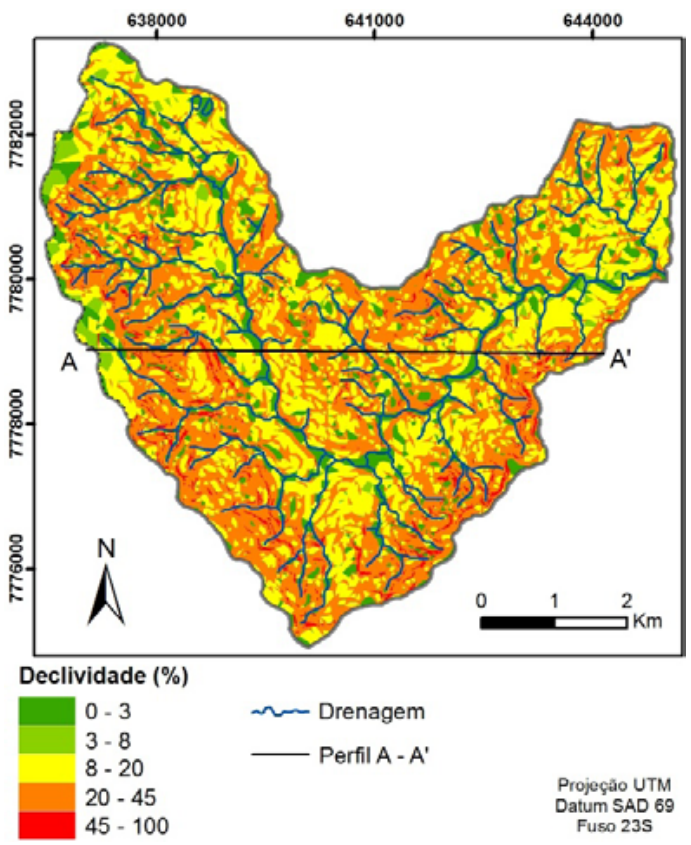




\section{Figura 6}

\section{Mapa pedológico da bacia do Ribeirão Preto}

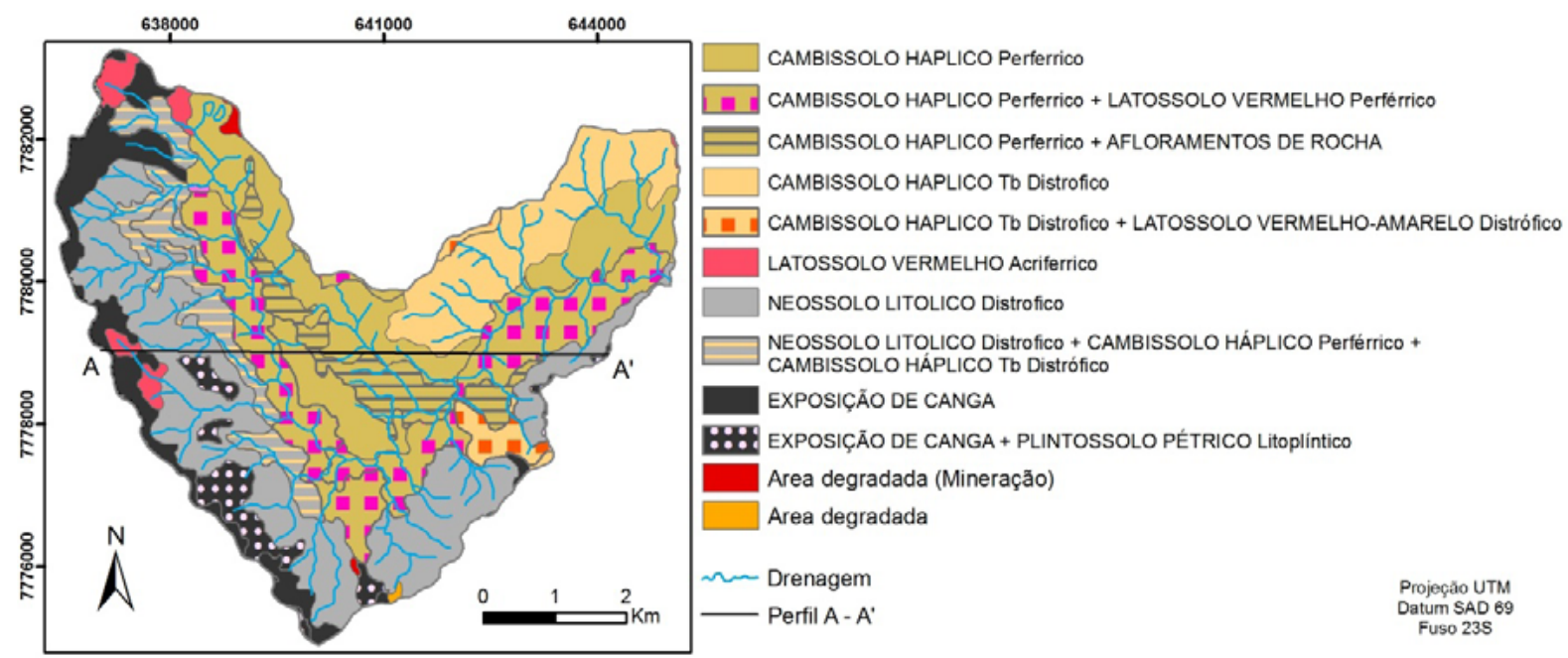

fonte: Shinzato e Carvalho Filho (2005).

\section{Figura 7}

Mapa de cobertura vegetal e uso da terra da bacia do Ribeirão Preto

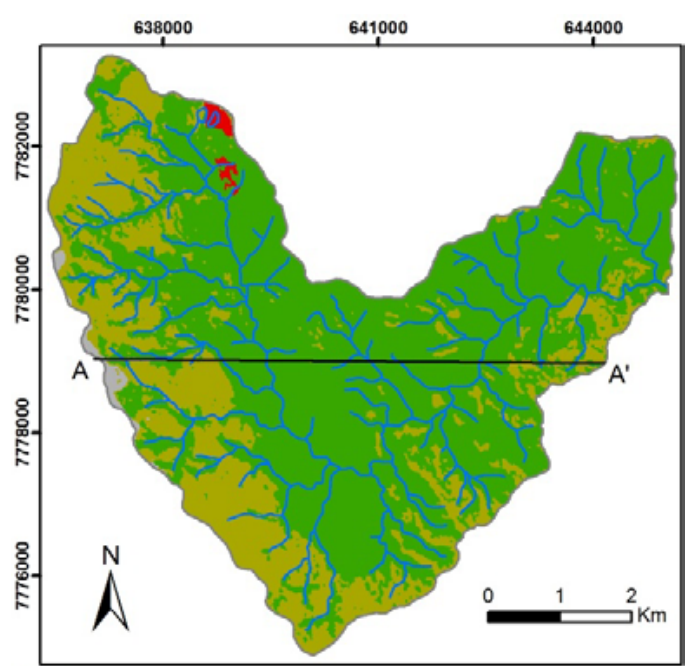

Floresta estacional semidecidual / mata de galeria

Campo limpo / campo sujo

Campo rupestre

Atividade mineral

$\sim$ Drenagem

$\longrightarrow$ Perfil A - $A^{\prime}$

Projeçăo UTM Datum SAD 69
Fuso 23S
Figura 8

Mapa geomorfológico da bacia do Ribeirão Preto

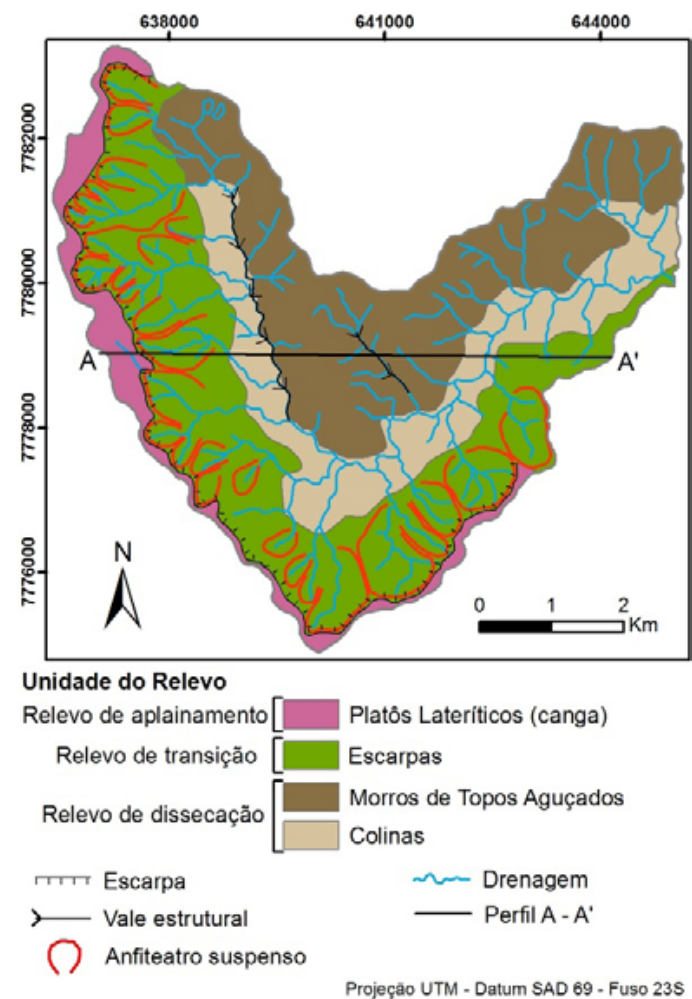

fonte: Medina, Dantas e Saadi (2005). 
$\mathrm{Na}$ escala analisada, o relevo foi um parâmetro eficiente para delimitação das unidades de paisagem, uma vez que refletiu relativa homogeneidade na interação entre os elementos (Figura 9 e 10) e processos. Dentro de cada atributo a grande variabilidade que existe acaba gerando uma diversidade que por vezes rompe com esta homogeneidade em função de um ou outro elemento, principalmente próximo ao contato entre as unidades. Mas na perspectiva geossistêmica isto é esperado, pois a homogeneidade dentro destas unidades não deve ser entendida como algo fixo (Sotchava, 1977) e a sua dinâmica interna não apresenta necessariamente uma homogeneidade fisionômica (Bertrand, 1972).

\section{Figura 9}

\section{Bloco-diagrama com as unidades de paisagem na bacia do Ribeirão Preto}

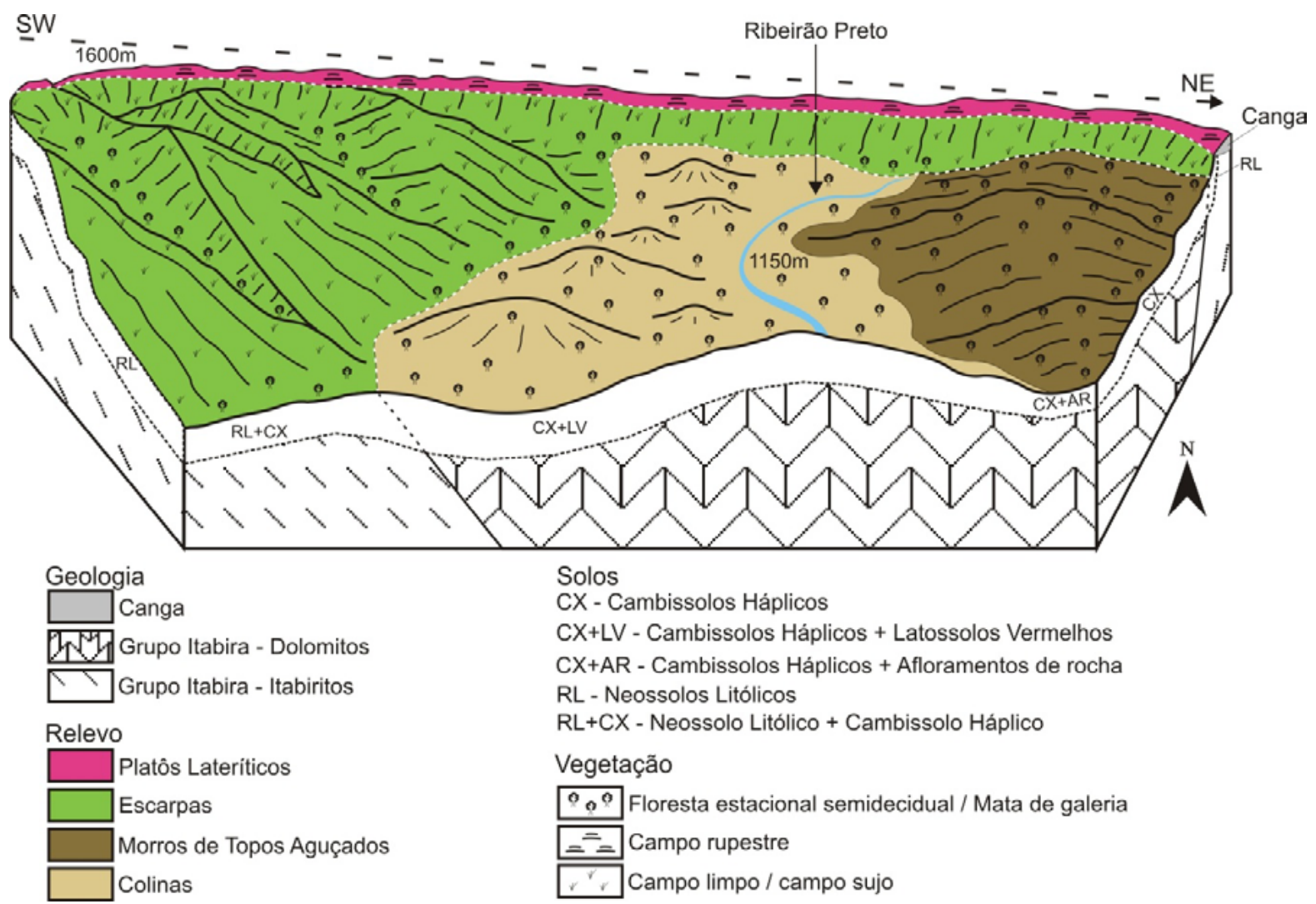




\section{Figura 10}

foto $\mathrm{A}$ - unidades com vista a montante a partir do médio curso do Ribeirão Preto foto $B$ - unidades com vista para o interior da bacia do Ribeirão Preto a partir do alto curso

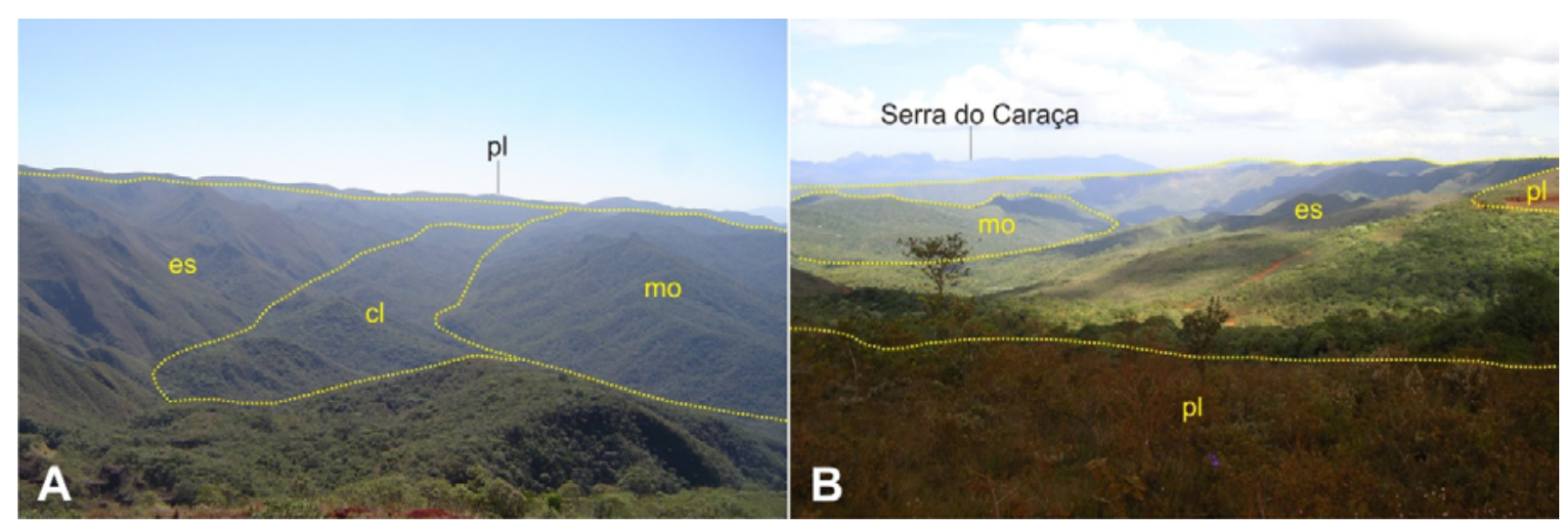

legenda: pl - platôs lateríticos; es - escarpas; mo - morros de topos aguçados; cl-colinas.

A Figura 11 e a Tabela 1 apresentam a distribuição dos diferentes elementos que compõem a paisagem da bacia do Ribeirão Preto. A Figura 11 apresenta o transecto $A-A^{\prime}$, que compreende a maior diversidade de elementos que se pode encontrar na bacia do Ribeirão Preto.

A Tabela 1 apresenta as unidades de relevo relacionadas à geologia, hipsometria, declividade, solos, cobertura vegetal e uso da terra. Foram identificadas unidades de colinas, morros, escarpas e platôs. 


\section{Figura 11}

\section{Perfil transversal da bacia do Ribeirão Preto}

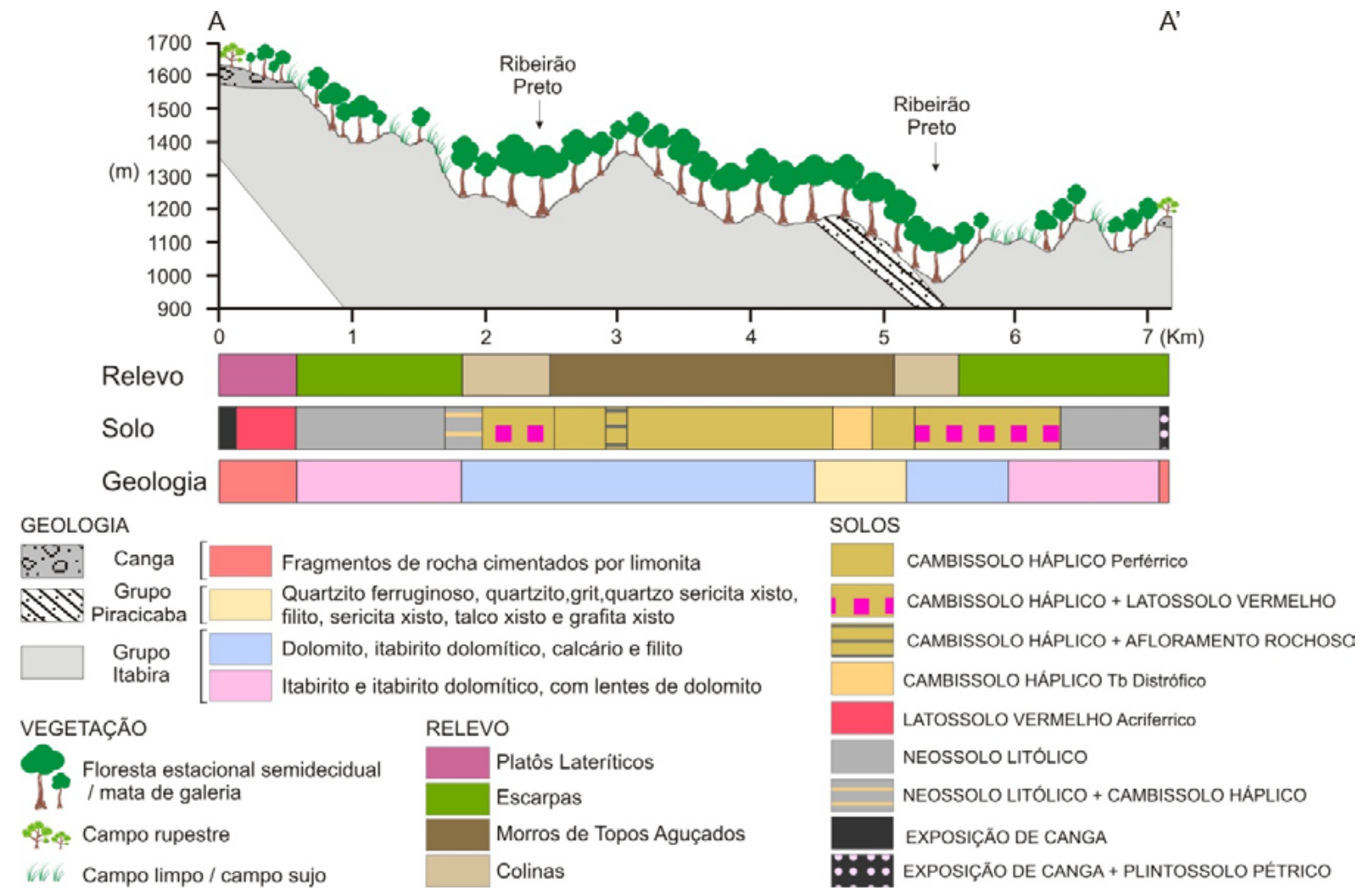

\section{Tabela 1}

\section{Relação dos elementos que predominam na paisagem da bacia do Ribeirão Preto}

\begin{tabular}{|c|c|c|c|c|c|c|}
\hline $\begin{array}{l}\text { elementos } \\
\text { da } \\
\text { paisagem }\end{array}$ & \multirow[t]{2}{*}{ geologia } & \multirow[t]{2}{*}{ hipsometria } & \multirow[t]{2}{*}{ declividade } & \multirow[t]{2}{*}{ solos } & \multirow[t]{2}{*}{$\begin{array}{l}\text { cobertura } \\
\text { vegetal }\end{array}$} & \multirow[t]{2}{*}{$\begin{array}{c}\text { problemas } \\
\text { decorrentes do uso } \\
\text { da terra }\end{array}$} \\
\hline unidades & & & & & & \\
\hline colinas & $\begin{array}{l}\text { - Dolomitos - } \\
\text { formação Gandarela } \\
\text { (Grupo Itabira) }\end{array}$ & $\begin{array}{l}\text { - amplitude de } \\
\text { até } 80 \mathrm{~m} .\end{array}$ & $\begin{array}{c}-<3 \% \\
- \text { entre } 8 \text { e } \\
20 \% .\end{array}$ & $-\mathrm{CX}+\mathrm{LV}$ & $\begin{array}{c}\text { - floresta } \\
\text { estacional } \\
\text { semidecidual }\end{array}$ & $\begin{array}{c}\text { - antiga sede da } \\
\text { fazenda Gandarela } \\
\text { abandonada }\end{array}$ \\
\hline $\begin{array}{l}\text { morros } \\
\text { de topos } \\
\text { aguçados }\end{array}$ & $\begin{array}{c}\text { - dolomitos - } \\
\text { Formação Gandarela } \\
\text { (Grupo Itabira) } \\
\text { - quartzitos e xistos - } \\
\text { Formação Cercadinho } \\
\text { (Grupo Piracicaba) }\end{array}$ & $\begin{array}{l}\text { - amplitude de } \\
\text { até } 240 \mathrm{~m} \text {. }\end{array}$ & $\begin{array}{c}\text { - entre } 8 \text { e } \\
45 \% .\end{array}$ & $\begin{array}{c}-C X \\
-C X+A R\end{array}$ & $\begin{array}{c}\text { - floresta } \\
\text { estacional } \\
\text { semidecidual }\end{array}$ & $\begin{array}{l}\text { - mineração } \\
\text { desativada }\end{array}$ \\
\hline escarpas & $\begin{array}{c}\text { - canga; } \\
\text { - itabiritos - Formação } \\
\text { Cauê (Grupo Itabira) }\end{array}$ & $\begin{array}{l}\text { - amplitudes } \\
\text { entre } 300 \text { e } \\
400 \mathrm{~m} .\end{array}$ & $\begin{array}{c}\text { - entre } 20 \text { e } \\
45 \% .\end{array}$ & $\begin{array}{c}-\mathrm{RL} \\
-\mathrm{RL}+\mathrm{CX} \\
-\mathrm{EC}+\mathrm{FF}\end{array}$ & $\begin{array}{l}\text { - campo limpo } \\
\text { - campo sujo } \\
\text { - mata de galeria }\end{array}$ & $\begin{array}{c}\text { - mineração de } \\
\text { bauxita desativada } \\
\text { - solo exposto } \\
\text { com formação de } \\
\text { voçoroca }\end{array}$ \\
\hline
\end{tabular}




\begin{tabular}{|c|c|c|c|c|c|c|}
\hline $\begin{array}{l}\text { elementos } \\
\qquad \mathrm{da} \\
\text { paisagem }\end{array}$ & \multirow[t]{2}{*}{ geologia } & \multirow[t]{2}{*}{ hipsometria } & \multirow[t]{2}{*}{ declividade } & \multirow[t]{2}{*}{ solos } & \multirow[t]{2}{*}{$\begin{array}{l}\text { cobertura } \\
\text { vegetal }\end{array}$} & \multirow[t]{2}{*}{$\begin{array}{c}\text { problemas } \\
\text { decorrentes do uso } \\
\text { da terra }\end{array}$} \\
\hline unidades & & & & & & \\
\hline $\begin{array}{l}\text { platôs } \\
\text { lateríticos }\end{array}$ & $\begin{array}{c}\text { - canga } \\
\text { - itabiritos - Formação } \\
\text { Cauê (Grupo Itabira) }\end{array}$ & $\begin{array}{c}\text { - entre as } \\
\text { cotas de } 1380 \\
\text { a } 1660 \mathrm{~m} .\end{array}$ & $-<20 \%$ & $\begin{array}{l}-\mathrm{EC} \\
-\mathrm{LV}\end{array}$ & $\begin{array}{l}\text { - campo } \\
\text { rupestre } \\
\text { ferruginoso; } \\
\text { - mata } \\
\text { estacional } \\
\text { semidecidual. }\end{array}$ & $\begin{array}{c}\text { - solo exposto } \\
\text { - mineração } \\
\text { exploratória de } \\
\text { minério de ferro } \\
\text { encerrada } \\
\text { - atividade de } \\
\text { MotoCross aos fins } \\
\text { de semana }\end{array}$ \\
\hline
\end{tabular}

\section{legenda}

solos: $\mathrm{CX}$ - cambissolo háplico; $\mathrm{CX}+\mathrm{LV}$ - cambissos háplico + latossolos vermelho; $\mathrm{CX}+\mathrm{AR}$ - cambissolos háplico + afloramento de rocha; LV - latossolo vermelho; RL - neossolo litólico; RL+CX = neossolo litólico + cambissolos háplico; $\mathrm{EC}$ - exposição de canga; $\mathrm{EC}+\mathrm{FF}$ - exposição de canga + plintossolo pétrico.

\section{Colinas}

A unidade de colinas do Ribeirão Preto está sobre os dolomitos da Formação Gandarela - Grupo Itabira. Segundo Salgado e outros (2004) são as rochas mais tenras e de menor resistência à desnudação. Essa unidade se localiza num patamar mais rebaixado em relação ao seu entorno, entre a unidade de escarpas e de morros de topos aguçados, condicionada estruturalmente ao longo de parte do curso fluvial principal. Segundo Medina e outros (2005), o Ribeirão Preto que antes desaguava suas águas no interior da sinclinal como afluente do ribeirão São João, foi capturado pelo rio Conceição (Figura 2). O estágio de entalhamento avançado do curso fluvial é devido, provavelmente, ao ajustamento do nível de base do rio Conceição, ao qual o Ribeirão Preto atualmente é afluente.

As declividades são menores que 3\% nas porções de talvegue e entre 8 e $20 \%$ nas vertentes das colinas. As colinas ocorrem nas duas margens do Ribeirão Preto sempre acompanhado o curso fluvial principal de montante a jusante onde a altitude varia dos 820 a $1.300 \mathrm{~m}$, com amplitudes em torno dos 40 a $80 \mathrm{~m}$. O relevo apresenta-se bem dissecado nas colinas de baixa altitude em relação às de entorno, geralmente apresentando topos suavizados a pouco angulosos. Devido a menor resistência aos processos intempéricos (Salgado et al., 2004) a rocha subjacente acaba proporcionando maior quantidade de material friável (Lamounier et al., 2010).

Os solos são pouco profundos, predominando cambissolos háplicos associados a latossolos vermelhos. Também ocorrem em menor proporção cambissolos háplicos, cambissolos háplicos associados a afloramentos rochosos, neossolos litólicos associados a cambissolos háplicos e cambissolos háplicos associados a latossolos vermelho-amarelos. Entretanto, os solos são mais profundos onde ocorrem latossolos. Nessa unidade se desenvolve densa vegetação, a floresta estacional semidecidual. Segundo Oliveira, Jacques e Shinzato (2005) apresenta árvores com até $20 \mathrm{~m}$ de altura que perdem parte de suas folhas na estação seca e estão relacionadas a solos profundos e maior retenção de umidade. Como na área a mata de galeria sofre influência da floresta estacional semidecidual é difícil estabelecer limites, aparecendo ambas como uma mancha homogênea. Segundo Shinzato e Carvalho Filho (2005) não foi constatada erosão aparente. Esse fato se deve, provavelmente, 
ao dossel contínuo que permite a interceptação das gotas de chuva e ao abundante aporte de matéria orgânica gerada sobre o solo que acaba por protegê-lo do impacto direto da chuva, minimizando os processos erosivos.

Em virtude do substrato geológico e da densa cobertura vegetal considera-se que a maior perda de massa ocorra por material em solução. Não foi identificado nenhum tipo de uso da terra estando a unidade em bom estado de conservação. Encontrou-se apenas algumas casas abandonadas, provavelmente da antiga fazenda Gandarela que no passado existiu na área. As características dessa unidade permitem que seja destinada a implantação de infraestruturas, desenvolvimento de atividades de visitação pública, educação ambiental, pesquisa e monitoramento ambiental. Essas áreas deverão ser avaliadas, caso a caso, no interior dessa unidade, em caso de estabelecimento de unidade de conservação.

\section{Morros de topos aguçados}

Os morros de topos aguçados da bacia do Ribeirão Preto estão sobre dolomitos da Formação Gandarela e quartzitos ferruginosos, filitos e xistos da Formação Cercadinho. As rochas desta unidade apresentam litologiasque, segundo Salgado e outros (2008), respondem diferentemente à desnudação. O relevo é composto por um conjunto de morros com cristas alinhadas predominantemente na direção NW-SE, que se direcionam para o curso fluvial principal, o Ribeirão Preto. Sua porção sobre os dolomitos encontra-se confinada entre dois vales estruturais gerando vales profundos e encaixados em $\mathrm{V}$. $O$ restante da área está sobre os quartzitos ferruginosos, xistos e filitos, ocupando as bordas elevadas da bacia e de vale encaixado.

O relevo movimentado com destacadas elevações e vales pronunciados estariam relacionadosàs litologias de diferentes resistências frenteà erosão diferencial. Jáos dolomitos, que ocupam as porções mais elevadas, estariam relacionados ao controle estrutural que comandou a desnudação por meio dos vales estruturais. Segundo Franco-Magalhães, Hackspacher e Saad (2010) o controle estrutural pode resultar em zonas preferenciais de desnudação levando determinadas áreas a maior remoção de material. Para Summerfield (1991) mesmo em litologias homogêneas o desenvolvimento de linhas de fraqueza facilitaria a incisão dos cursos fluviais. Este compartimento está entre 1000 e $1460 \mathrm{~m}$ de altitude, com amplitudes em torno de 80 a $240 \mathrm{~m}$. As declividades variam de forte a moderada, entre $8 \mathrm{e}$ $45 \%$. A topografia movimentada apresenta vertentes retilíneas a côncavas com mergulho das rochas variando de 35 a $60^{\circ}$, o que facilita a ação dos processos desnudacionais.

Os solos que predominam são cambissolos háplicos e cambissolos háplicos associados a afloramentos rochosos, muito influenciados pelo relevo movimentado. Também ocorrem em menor proporção cambissolos háplicos associados a latossolos vermelhos e cambissolos háplicos associados a latossolos vermelho-amarelos. Sobre os solos se estabelece floresta estacional semidecidual, provavelmente em função da umidade e das rochas mais susceptíveis ao intemperismo como dolomitos, xistos e filitos (Salgado et al., 2004, 2008; Lamounier et al., 2010).

A vegetação de dossel fechado acaba se tornando uma proteção para o impacto da chuva, produzindo cobertura vegetal morta que facilita a infiltração e impede os processos erosivos mais intensos. Ainda assim, segundo Ibram (2003), sobre os dolomitos o relevo

declivoso e a baixa permeabilidade, levam a escoamento superficial muito rápido, o que 
facilita a ocorrência de processos erosivos. Já sobre os quartzitos e filitos a permeabilidade varia em função do grau de alteração do material levando a escoamento superficial moderado. Estas rochas quando cortadas ou revolvidas levam a instalação de processos erosivos e escorregamentos. Foi possível constatar na unidade que as elevadas declividades acabam favorecendo o escoamento superficial semiconcentrado gerando ravinamentos, atualmente estabilizados e revestidos por densa vegetação.

Essa unidade apresenta-se bem conservada, sendo encontrada apenas uma mina desativada no contato dos dolomitos com os itabiritos. A manutenção da vegetação, assim como a recuperação das áreas degradadas é importante para a proteção e estabilidade dos taludes. As características dessa unidade sugerem o estabelecimento de recuperação para a porção antropizada e de pesquisa científica e monitoramento ambiental para o restante da área, sem quaisquer alterações humanas, em caso de implantação de unidade de conservação.

\section{Escarpas}

A unidade de escarpas na bacia do Ribeirão Preto está relacionada principalmente às cangas e itabiritos da Formação Cauê - Grupo Itabira. Entretanto, não são itabiritos puros, ocorrendo associados a itabirito dolomítico e com lentes de dolomito. Suas escarpas situamse entre os 920 e $1.600 \mathrm{~m}$ de altitude com desníveis entre 300 e $400 \mathrm{~m}$, predominando declividades fortes entre 20 e $45 \%$. Segundo Medina e outros (2005), suas vertentes muitos íngremes formam anfiteatros suspensos profundamente dissecados sobre os itabiritos. Para Ibram (2003) as porções mais intemperizadas resultam da dissolução da silica e/ou carbonatos. É possível que a formação destes anfiteatros esteja relacionada à dissolução dos dolomitos, uma vez que as rochas da escarpa não são constituídas por itabiritos puros.

Os solos são rasos em virtude do material de origem e da declividade elevada, predominando os neossolos litólicos e neossolos litólicos associados a cambissolos háplicos. Exposição de canga associada a plintossolos pétricos também ocorrem em declividades menores, entre 8 e $20 \%$. Os solos rasos e distróficos, por vezes com teores de alumínio em níveis tóxicos, bem como a litologia não permitem a existência de vegetação exuberante, formando-se uma associação mista de campos limpos e campos sujos. Os campos limpos são constituídos por vegetação predominantemente herbácea, com poucos arbustos e sem árvores enquanto os campos sujos por vegetação herbáceo-arbustiva, com arbustos e subarbustos. Os anfiteatros suspensos indicam áreas de desnudação acelerada pelos fluxos concentrados devido à alta declividade, com solos rasos e vegetação de campos limpos e campos sujos em suas bordas. Constituem as cabeceiras de drenagem que formam as nascentes dos diversos córregos afluentes do Ribeirão Preto. O interior dos anfiteatros indica a presença de acúmulo de sedimentos e de umidade pela existência de mata de galeria. Esta apresenta transição progressiva em direção aos campos sujos e campos limpos.

As escarpas apresentam-se bem conservadas, inexistindo qualquer tipo de uso atual na área. No entanto, foi identificada uma mina de bauxita desativada e, nas proximidades, processo erosivo desenvolvido nas bordas de um anfiteatro que exibe solo exposto. Nesta porção, foi constatada a ocorrência de deslizamentos de terra que promovem o recuo lateral daescarpa, gerando concavidades abaixo das formações vegetais sobre substrato ferruginoso e que posteriormente acabam colapsando. Como as declividades são muito elevadas, 
qualquer tipo de atividade que retire sua vegetação pode comprometer a estabilidade dos taludes incorrendo em processos erosivos acelerados e movimentos de massa. A manutenção da vegetação e a recuperação das áreas degradadas são importantes para a estabilidade destes taludes. As características dessa unidade sugerem o estabelecimento de recuperação para os processos erosivos e áreas antropizadas, bem como de pesquisa científica e monitoramento ambiental para o restante da área sem quaisquer alterações humanas, em caso de implantação de unidade de conservação.

\section{Platôs lateríticos}

Os platôs lateríticos se localizam no divisor da bacia do Ribeirão Preto, na porção que divide as bacias dos rios das Velhas e Doce. Encontram-se sobre as cangas em superfície com altitudes médias em torno de $1600 \mathrm{~m}$, variando entre 1380 e $1660 \mathrm{~m}$ e declividades moderadas a muito fracas, inferiores a $20 \%$, que formam rampas em direção à bacia hidrográfica do Ribeirão Preto. Estas extensas formações de canga contribuem para a manutenção de parte da Sinclinal suspensa (Medina et al. , 2005). É um material duro e de alta resistência aos processos erosivos (Ibram, 2003; Shuster et al., 2012).

O solo nestas porções é praticamente inexiste, predominando a exposição de Canga sobre a qual se formam campos rupestres ferruginosos. São espécies herbáceo-arbustivas, ora dominando mais as espécies herbáceas ora as arbustivas. Segundo Embrapa (1998) estas espécies ocorrem em altitudes mais elevadas, diretamente sobre as rochas ou sobre suas fendas e geralmente onde há ventos constantes, dias quentes e noites frias. No entanto, por ser uma espécie nativa de áreas ferruginosas apresentam uma fitofisionomia completamente diferente dos campos rupestres que se encontram sobre os quartzitos. Segundo Carmo (2010) estes ambientes são os sistemas ecológicos mais ameaçados do Brasil devido a sua associação com as jazidas de minérios de ferro e se constituem em importante sistema de aquíferos. Além disso, segundo o mesmo autor, têm flora com grande diversidade de espécies endêmicas ameaçadas de extinção. Algumas manchas de latossolos vermelhos também ocorrem no topo das superfícies aplainadas onde se forma a floresta estacional semidecidual de menor porte arbóreo, de 3 a $5 \mathrm{~m}$ de altura.

Esta unidade é utilizada aos finais de semana para atividades de trilha de MotoCross. Também foram encontrados vários pontos com solo exposto em virtude de sondagens recentes para avaliação de jazida e levantamento de dados para o estabelecimento de empreendimentos minerários. Sabe-se que na área há um conflito de interesses entre a mineração e conservação desses ambientes, tendo sido aprovado até o momento um empreendimento minerário próximo à borda SW da bacia do Ribeirão Preto. Empreendimentos minerários que venham a se estabelecer nestas porções podem comprometer tanto os campos rupestres quanto os aquíferos e sua disponibilidade de água para a região metropolitana de Belo Horizonte. As características dessa unidade permitem que seja destinada a implantação de infraestruturas em áreas antropizadas, desenvolvimento de atividades de visitação pública controlada, educação ambiental, pesquisa e monitoramento ambiental. Essas áreas deverão ser avaliadas, caso a caso, no interior dessa unidade, em caso de estabelecimento de unidade de conservação. 


\section{Considerações finais}

A escolha do relevo pelo conjunto de formas semelhantes para delimitar as unidades de paisagem foi adequada, uma vez que refletiu significativas relações entre geologia, relevo, solo, cobertura vegetal e uso da terra. Cada unidade tem características próprias em função da interação de seus elementos.

A litoestrutura tem grande domínio na configuração da paisagem pela erosão diferencial e pelo sistema de falhas e fraturas, proporcionando áreas mais suscetíveis à desnudação e influenciando o modelado movimentado do relevo, que se distribui em diferentes unidades de paisagem. $\mathrm{O}$ material de origem, em conjunto com a variedade de formas do relevo, atua diretamente na formação dos solos, que tendem a aumentar progressivamente o grau de evolução do topo para a base das vertentes.

Os neossolos litólicos e cambissolos háplicos predominam, apesar de outros tipos de solos em associação, como os latossolos. Os campos limpos sempre associados aos campos sujos ocorrem sobre solos mais rasos, normalmente neossolos litólicos, enquanto os campos rupestres se situam sobre cangas. A floresta estacional semidecidual predomina sobre cambissolos háplicos e latossolos associados a cambissolos háplicos. E, por último, as matas de galeria sempre associadas aos cursos fluviais.

As características do meio físico da Serra do Gandarela a tornam extremamente frágil frente às intervenções antrópicas. Apesar de se encontrar em significativo estado de conservação, a retirada de sua cobertura vegetal pode levar a acelerados processos erosivos e movimentos de massa. Sua geologia diversificada e fraturada, com estrutura planar, acamamentos e xistosidades, pode levar a escorregamentos e quedas de blocos por meio de intervenções inadequadas nos taludes. Solos rasos não favorecem o armazenamento de água, levando rapidamente a atingir a capacidade de campo, o que pode levar, nas escarpas mais íngremes, a movimentos de massa, mesmo com vegetação. Além disso, a retirada da vegetação causa menor infiltração com a exposição solo predominantemente raso e pouco coeso, favorecendo os processos erosivos mais intensos.

Em virtude de suas características ambientais e da significativa beleza cênica de suas paisagens, o uso mais indicado para a área é como unidade de conservação, permitindo a manutenção desses ambientes. Caso a área venha a se tornar uma unidade de conservação, seu plano de manejo deve levar em conta suas fragilidades, decorrentes em grande parte da litoestrutura. As unidades de colinas e platôs lateríticos favorecem o uso mais diversificado e pela atual condição com pequenas com alterações antrópicas e grandes áreas ainda preservadas podem ser destinadas à implantação de infraestruturas, atividades de visitação pública, educação ambiental, pesquisa e monitoramento ambiental. As unidades de escarpas e morros de topos aguçados são mais indicadas à pesquisa científica e monitoramento ambiental, sem quaisquer alterações humanas. Para conciliação entre conservação e mineração, há outras porções da Serra do Gandarela a NE (Figuras 1 e 2), e mesmo do Quadrilátero Ferrífero, compreendidas pelo Supergrupo Minas, que poderiam fornecer condições para a exploração mineral causando menor impacto possível.

\section{Referências}

ALKMIM, F. F.; MARSHAK, S. Transamazonian Orogeny in the Southern São Francisco 
Craton Region, Minas Gerais, Brazil: evidence for Paleoproterozoic collision and collapse in the Quadrilátero Ferrifero. Precambrian Research, n. 90, p. 29-58, 1998.

BERTRAND, G. Paisagem e geografia física global: esboço metodológico. Caderno de Ciências da Terra, São Paulo, v. 13, p. 1-27, 1972.

CARMO, F. F. Importância ambiental e estado de conservação dos ecossistemas de cangas no Quadrilátero Ferrífero e proposta de áreas-alvo para a investigação e proteção da biodiversidade em Minas Gerais. Dissertação (Mestrado em Ecologia, Conservação e Manejo da Vida Silvestre) - Instituto de Ciências Biológicas, Universidade Federal de Minas Gerais, Belo Horizonte, 2010.

EMBRAPA. EMPRESA BRASILEIRA DE PESQUISA AGROPECUÁRIA. Centro de Pesquisa Agropecuária dos Cerrados. Cerrado: ambiente e flora. Planaltina, DF: Embrapa/CPAC, 1998.

FRAGA, A; AYER, F. Proteção para a serra do Gandarela é garantida pela Justiça. Estado de Minas, Belo Horizonte, 20 jun. 2012. Disponível em: http://www. em.com.br/app/noticia/gerais/2012/06/20/interna gerais,301200/protecao-para-aserra-do-gandarela-e-garantida-pela-justica.shtml. Acesso em: 20 jun. 2012.

FRANCO-MAGALHÃES, A. O. B.; HACKSPACHER, P. C.; SAAD, A. R. Exumação tectônicaereativaçãodepaleolineamentosno ArcodePontaGrossa:termocronologia por traços de fissão em apatitas. Revista Brasileira de Geociências, São Paulo, v. 40, n. 2, p. 184-195, 2010.

IBRAM. INSTITUTO BRASILEIRO DE MINERAÇÃO. Contribuição do Ibram para o zoneamento ecológico-econômico e o planejamento ambiental de municípios integrantes da APA-Sul RMBH. Brasília, DF: Ibram, 2003.

ICMBIO. INSTITUTO CHICO MENDES DE CONSERVAÇÃO DA BIODIVERSIDADE. Proposta de criação do Parque Nacional Serra do Gandarela. Brasilia, DF: ICMBio, set. 2010.

LAMOUNIER, W. M. et al. A influência da litologia na distribuição da cobertura vegetal e no uso do solo na Serra do Gandarela - Quadrilátero Ferrífero-MG. Geografias, Belo Horizonte, v. 6, n. 1, p. 152-165, 2010.

LOBATO, L. M. et al. Projeto geologia do Quadrilátero Ferrífero: integração e correção cartográfica em SIG com nota explicativa. Belo Horizonte: Codemig, 
MEDINA, A. I.; DANTAS, M. E.; SAADI, A. Projeto APA Sul RMBH: estudos do meio físico, geomorfologia. Belo Horizonte: CPRM/Embrapa/Semad/Cemig, 2005.

MONTEIRO, C. A. Geossistema: a história de uma procura. São Paulo. Contexto, 2001 .

OliVEIRA, G. S. R.; JACQUES, P. D.; SHINZATO, E. Projeto APA Sul RMBH: estudos do meio físico, cobertura e uso da terra. Belo Horizonte: CPRM/Embrapa/ Semad/Cemig, 2005.

SALGADO, A. A. R. et al. Relief evolution of the Quadrilátero Ferrifero (Minas Gerais, Brazil) by means of $\left({ }^{10} \mathrm{Be}\right)$ cosmogenic nuclei. Zeitschrift fur Geomorphologie, Berlin, v. 52, n. 3, p. 317-323, 2008.

- O papel da denudação geoquímica no processo de erosão diferencial no Quadrilátero Ferrífero-MG. Revista Brasileira de Geomorfologia (Online), São Paulo, v. 5, n. 1, p. 55-69, 2004

SHINZATO, E.; CARVAlHO FILHO, A. Projeto APA Sul RMBH: estudos do meio físico, pedologia. Belo Horizonte: CPRM/Embrapa/Semad/Cemig, 2005.

SHUSTER, D. L. et al. Cosmogenic 3He in hematite and goethite from Brasilina "canga" duricrust demonstrates the extreme stability of these surfaces. Earth Planetary Science Letters, n. 329-330, p. 41-50, 2012.

SILVA, J. R.; SALGADO, A. A. R. Mapeamento das unidades de relevo da região da Serra do Gandarela - Quadrilátero Ferrífero-MG. Geografias, Belo Horizonte, v. 5, n. 2, p. 107-125, 2009.

SOTCHAVA, V. B. O estudo de geossistemas. Métodos em Questão, São Paulo, n. 16, p. 1-51, 1977.

SUMMERFIELD, M. A. Global Geomorphology: an introduction of the study of landforms. Essex, UK: Longman Scientific E Technical, 1991.

VARAJÃO, C. A. C. A questão da correlação das superfícies de erosão do Quadrilátero Ferrífero, Minas Gerais. Revista Brasileira de Geociências, São Paulo, v. 21, n. 2, p. 138-145, 1991. 